\title{
Determination of Water Evaporation Rates in Gas Diffusion Layers of Fuel Cells
}

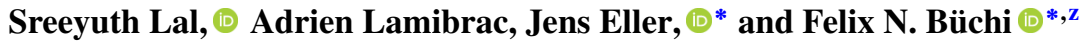 \\ Electrochemistry Laboratory, Paul Scherrer Institute, CH-5232 Villigen PSI, Switzerland
}

\begin{abstract}
The efficiency of polymer electrolyte fuel cells is closely linked to effective heat and water management. Evaporation of water in the gas diffusion layers (GDL) is an important process influencing water management and can even be used for evaporative cooling. In this study, evaporation rates in Toray-GDL materials are obtained for different temperatures, gas flow rates, carrier gases and water saturation levels. Evaporation rates are correlated with water distribution profiles in the GDL, obtained using X-ray tomographic microscopy imaging. The influence of temperature on the evaporation rates is predicted by considering the effect of temperature on vapor diffusion alone. However, changing the carrier gas type points to a deviation from diffusive-driven vapor transport, which could be due to entrainment of gas inside the GDL, among other factors.

(C) The Author(s) 2018. Published by ECS. This is an open access article distributed under the terms of the Creative Commons Attribution 4.0 License (CC BY, http://creativecommons.org/licenses/by/4.0/), which permits unrestricted reuse of the work in any medium, provided the original work is properly cited. [DOI: $10.1149 / 2.0831809$ jes]

(cc) BY
\end{abstract}

Manuscript submitted March 8, 2018; revised manuscript received May 29, 2018. Published June 9, 2018.

Polymer electrolyte fuel cells (PEFC) efficiently convert the chemical energy stored in hydrogen to electrical energy, with water and heat as the byproducts. PEFCs are therefore considered a key technology for future hydrogen-based energy scenarios, especially in the mobility and energy storage sectors, as the usage of renewable electricity gains momentum worldwide. The central component of PEFCs is the membrane-electrode-assembly (MEA), which consists of a membrane at the center that is coated with catalyst layers (CL) on both sides, which are contacted by gas diffusion layers (GDL). Water management in the MEA is a critical topic that is closely related to power density and durability of PEFCs. ${ }^{1}$ Water management (i.e. having maximum water content in the membrane and a minimum saturation in the porous layers) is a complex issue governed by the fluid and energy flows in the MEA. Most of this complexity arises from the fluxes of heat and water in the GDLs, which are difficult to localize and quantify.

Gas diffusion layers are porous structures with porosities in the range of $70-85 \%$ and average pore sizes around $10-40 \mu \mathrm{m}^{2}$ The GDL materials have to provide maximum heat and electron conductivity in the solid structure while simultaneously ensuring high permeability of the reactant gases, product water and water vapor in the void. At low operating-temperatures or high current densities, gas transport in the pore space can be significantly hindered by liquid water occupying pore space, especially at the cathode side. Consequently, oxygen transport to the cathode CL is significantly affected, which in turn reduces fuel cell performance or efficiency. ${ }^{3}$

Heat and water management in the fuel cell can be simplified to some extent if the concept of evaporative cooling is utilized. ${ }^{4}$ On a system level, the biggest advantage of such an approach is the reduction of fuel cell system complexity by eliminating the need for separate coolant and humidification loops.

Wood et al. ${ }^{5}$ showed that evaporation by incoming airflow is an effective way of water removal at the cathode GDL, while Warburton et al. ${ }^{6}$ demonstrated a $30 \mathrm{kWe}$ evaporatively cooled stack with cold start ability. Hwang \& $\mathrm{Kim}^{7}$ introduced a simultaneous cathode humidification and evaporative cooling system in a five-cell PEMFC stack. Expectedly, the evaporation rate is found to be larger at higher operating temperatures and higher water injection flow rates in their study. UTC Power has advanced the use of porous bipolar plates for providing a direct pathway for water between gas channels and dedicated coolant channels in the membrane to facilitate humidification and evaporative cooling. ${ }^{8}$ Fly $\&$ Thring ${ }^{9}$ used numerical simulations to investigate temperature fluctuations in a stack due to evaporation, with no analysis at the component level. The influence of temperature

*Electrochemical Society Member

${ }^{\text {zE}}$-mail: felix.buechi@psi.ch on injection in GDLs has hardly received any attention in literature, with the exception of Shrestha \& Gostick ${ }^{10}$ who observed that the wettability of GDLs treated with hydrophobic PTFE coatings remained constant with temperature. The use of engineered pathways for water in GDLs ${ }^{11}$ was also recently proposed.

Despite the interest in water removal and cooling with evaporation, phase change in GDLs is still not well-quantified, as most of the studies related to two phase flow in GDL analyze non-phase change phenomena such as drainage, imbibition and capillary redistribution. ${ }^{12-16}$ Only a few data is available on phase change in GDLs. Chapius et al. ${ }^{17}$ studied evaporation in specially perforated GDLs while Cho \& Mench $^{18}$ investigated evaporation from SGL and Carbel GDLs as a function of air flow rates and the effects of hydrophobicity ${ }^{19}$ on the evaporation process. The shape of the evaporation front was only postulated without actually visualizing it. Also, the available amount of numerical studies on phase-change in GDL ${ }^{20-22}$ is limited.

In the last few years, there have been rapid developments in the application of X-ray tomographic microscopy (XTM) for visualizing water distribution in GDL. ${ }^{23-26}$ This provides the crucial missing link in understanding the correlation of liquid water distribution and its surface area to the evaporation rate in GDL under different thermodynamic and material conditions. Zenyuk et al. ${ }^{27}$ visualized the evaporating water front in GDLs for the first time with XTM. The water front imaged using XTM was also used as an input to simulate evaporation using a finite element model. Zenyuk et al. ${ }^{27}$ concluded that evaporation in GDL is diffusion limited. Evaporation rates close to room temperature are found to be proportional to porosity and temperature and inversely proportional to tortuosity and material thickness. Although Zenyuk et al. ${ }^{27}$ used two different carrier gases $\left(\mathrm{He}\right.$ and $\mathrm{N}_{2}$ ), their results cannot be compared since the GDL samples are different for the two gas types. Safi et al. ${ }^{28}$ carried out experiments and Lattice Boltzmann simulations of evaporation in GDL, while also focusing on the influence of evaporation currents on gas flow within the GDL. The gas speed range $(0.4-1.6 \mathrm{~m} / \mathrm{s})$ and cell temperature $\left(30^{\circ} \mathrm{C}\right)$ in their study is, however, much lower than those considered in this study.

There is a research gap in the understanding of the correlation of liquid water distribution, under well-defined boundary conditions, and its surface area to the evaporation rate in GDL under different thermodynamic and material conditions. In this study, water is filled from the bottom into GDLs and evaporated to a dry carrier gas flowing at technically relevant speeds in a channel on the surface of the GDL, simulating electrochemically produced water in a fuel cell where no condensation occurs. Data is obtained from systematic measurements analyzing the influence of temperature, gas flow rate, carrier gas type, GDL thickness and GDL saturation level on the evaporation rate of liquid water from the GDL. The evaporation experiments are combined with XTM imaging to correlate global evaporation fluxes with local saturation distributions. 
Table I. Compression and porosity characteristics from XTM images.

\begin{tabular}{|c|c|c|c|c|c|c|c|}
\hline \multirow[b]{2}{*}{ GDL } & \multirow[b]{2}{*}{$\begin{array}{l}\text { Temperature } \\
{\left[{ }^{\circ} \mathrm{C}\right]}\end{array}$} & \multirow[b]{2}{*}{$\begin{array}{l}\text { Initial thickness } \\
{[\mu \mathrm{m}]}\end{array}$} & \multirow[b]{2}{*}{$\begin{array}{l}\text { Compressed thickness } \\
{[\mu \mathrm{m}]}\end{array}$} & \multirow[b]{2}{*}{$\begin{array}{l}\text { Compression } \\
{[\%]}\end{array}$} & \multirow[b]{2}{*}{$\begin{array}{l}\text { Initial porosity } \\
{[-]}\end{array}$} & \multicolumn{2}{|c|}{ Compressed porosity } \\
\hline & & & & & & $\begin{array}{l}\text { X-ray CT } \\
{[-]}\end{array}$ & $\begin{array}{l}\text { Eq. } 1 \\
{[-]}\end{array}$ \\
\hline TGP-H120 & 27 & 370 & 317 & 14 & 0.74 & 0.69 & 0.70 \\
\hline TGP-H060 & 60 & 190 & 163 & 14 & 0.76 & 0.71 & 0.72 \\
\hline TGP-H120 & 60 & 370 & 322 & 13 & 0.74 & 0.69 & 0.70 \\
\hline
\end{tabular}

\section{Materials and Methods}

Materials.-GDLs from Toray with two different thicknesses are used: Toray TGP-H060 and Toray TGP-H120 (both without MPL, Toray Industries, Japan) with $10 \mathrm{wt} \%$ PTFE loading. The samples are compressed during the experiment. In the channel/rib type set-up (see Figure 1), the level of compression is not uniform across the sample with the compression being lower under the flow channel than the rib. The region of interest (RoI), where evaporation occurs, is the area shown in Figure 1, at the cross-section of the flow channel and the imbibed area. The compression and porosity characteristics properties of the RoI of both the GDL types are given in Table I.

Since XTM images were obtained with different samples around room temperature $\left(27^{\circ} \mathrm{C}\right)$ and at $60^{\circ} \mathrm{C}$, calculations are given for both temperatures in Table I. Even within the RoI, the GDL compression is slightly non-uniform with the compression being the highest close to the flow channel edge and the lowest at the center of the flow channel. In Table I, the initial thickness is taken from supplier data while the compressed thickness at the center of the flow channel is determined from XTM images. The initial porosity of TGP-H120 with $10 \%$ PTFE coating is taken from the mercury intrusion porosity (MIP) measurements of Lobato et al. ${ }^{29}$ while the initial porosity of TGP-
H060 with 10\% PTFE coating is interpolated from the measurements of Park et al. ${ }^{30}$ In Table I, the GDL thickness at the center of the flow channel is considered as the compressed thickness. For determining the compressed porosity, two methods are used. First, the compressed porosity is directly determined from the segmented XTM images. Second, the compressed porosity is calculated as:

$$
\varepsilon_{c}=1-\frac{\delta_{0}}{\delta_{c}}\left(1-\varepsilon_{0}\right)
$$

where $\varepsilon_{0}$ and $\varepsilon_{c}$ are the initial and compressed porosities and $\delta_{0}$ and $\delta_{c}$ are the initial and compressed thicknesses respectively. The compressed porosity values from the two methods show reasonable agreement, indicating the accuracy of the segmentation process.

Evaporation experiments.-The schematic of the experimental setup is shown in Figure 1. The setup consists of a $6 \mathrm{~mm}$ diameter GDL sample compressed in the sample holder between a flow field plate with a single channel at the top and an injection plate at the bottom, both made from graphite. Between the GDL and the injection plate, a $50 \mu \mathrm{m}$-thick FEP foil with a laser-cut $1 \times 2 \mathrm{~mm}^{2}$ opening at the center is placed to define an accurate injection domain. The

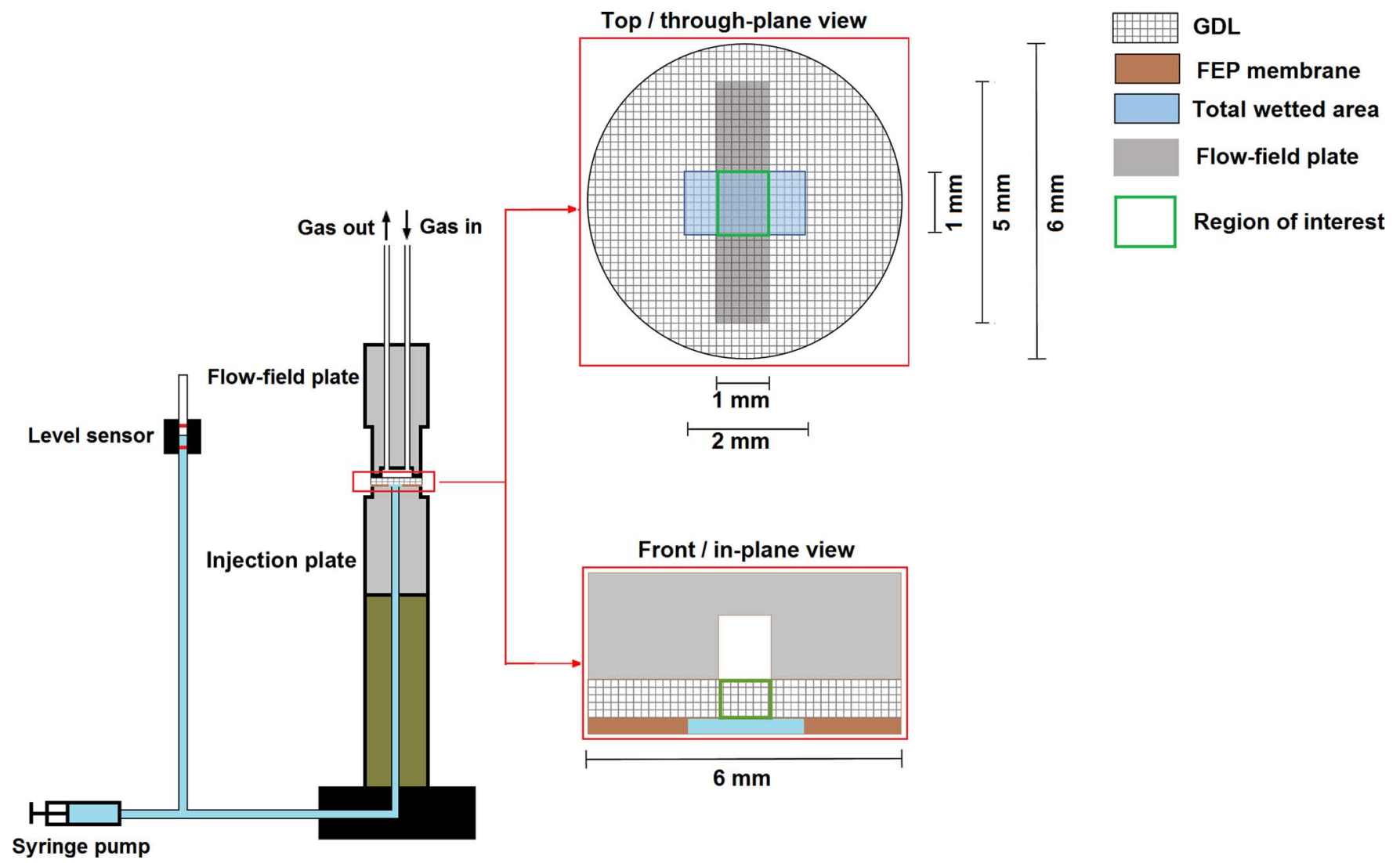

Figure 1. Experimental setup used for studying evaporation rates. 
Table II. Testing conditions of the experiments, along with the corresponding figures.

\begin{tabular}{lllllll}
\multicolumn{1}{c}{ Parameter } & Figures & GDL type & Gas type & Gas speed $\left[\mathrm{m} \mathrm{s}^{-1}\right]$ & Liquid pressure $[\mathrm{mbar}]$ & Temperature $\left[{ }^{\circ} \mathrm{C}\right]$ \\
\hline Saturation profiles & 2 & TGPH 060/120 & N2 & 6 & $20-45$ & 27,60 \\
Influence of saturation & $3-5$ & TGPH 060/120 & N2 & 6 & $20-45$ & 60 \\
Influence of temperature & 6 & TGPH 060/120 & N2/H2 & 6 & 20 & $40-80$ \\
Influence of gas flow & 7 & TGPH 060/120 & N2/H2 & $2-10$ & 20
\end{tabular}

gas channel at the top of the GDL is perpendicular to the membrane opening at the bottom, such that the cross-section area that overlaps both the membrane opening and the gas channel is $1 \mathrm{~mm}^{2}$, as shown in Figure 1. This overlapping area is the region of interest (RoI) in this study. The geometry was designed in order to have (i) a relevant channel geometry, allowing for (ii) relevant gas speeds over the GDL; (iii) the water pool having a well-defined length in direction of the gas flow; (iv) this length being short enough to limit gas saturation effects in the channel and long enough to be above a representative length with respect to pore size distribution of the GDL; (v) the water pool width is extended beneath the ribs to limit lateral boundary effects of accurate placement of the channel over the "water pool". This should provide clear boundary conditions if our results are used for validation of model calculations.

The temperature of the setup is controlled by two cartridge heaters in the flow field and injection plates, also the supplied gas is heated to the same temperature as the flow field. Dry gas is supplied to the channel at the top surface of the GDL for vapor removal. Water is injected from the bottom of the GDL using a syringe pump (KDS Legato 110, USA) at a rate of $10 \mu \mathrm{L} / \mathrm{min}$. Water saturation in the GDL is controlled by monitoring the capillary pressure using a water column connected in parallel to the sample holder. The global evaporation rate in the GDL is computed from the time required for the water column height to decrease by $10 \mathrm{~mm}(1.96 \mu \mathrm{L})$ from $H_{\text {ref }}+5 \mathrm{~mm}$ to $H_{\text {ref }}-5 \mathrm{~mm}$, where $H_{\text {ref }}$ corresponds to the equivalent water column height of the capillary pressure being investigated.

This time period is measured using an automated water level sensor. All evaporation measurements in this study are done below the breakthrough pressure i.e. the pressure at which water forms a percolation path from the bottom to the top of the GDL. For given operating conditions, evaporation is measured in three different samples to ensure reproducibility, and within each sample, each point is measured three times. All sensors and setup parts (pump, level-sensor, gas flowmeter, heaters) are controlled using LabVIEW. In this work, first, the water saturation profiles at different capillary pressures are analyzed, followed by the analysis of the influence of saturation, gas flow rate and temperature on evaporation rates in GDL. The testing conditions for each of these studies are listed in Table II. It is seen from Table II that the reference gas flow velocity, capillary pressure and temperature are $6 \mathrm{~m} / \mathrm{s}, 20 \mathrm{mbar}$ and $60^{\circ} \mathrm{C}$ respectively.

XTM imaging and segmentation.-X-ray tomographic microscopy scans are taken with a laboratory CT scanner (Nanotom $\mathrm{m}$, General Electric). Imaging is used to visualize liquid water distributions in the GDL at different capillary pressures, as specified in Table II. At the beginning of each scan, water is pumped to the desired capillary pressure and the evaporation rate at that capillary pressure is first measured. The pumping mode of the syringe pump is then changed to compensation mode i.e. the water level is maintained at a constant capillary pressure level around the upper level sensor by compensating the evaporated water. The duration of the compensation mode is set equal to the scanning time of each XTM scan such that the injected water remains at the same capillary pressure throughout the scan. After each scan, the evaporation rate is again measured to verify that it is similar to the one measured before the scan. XTM scans at room temperature $\left(27^{\circ} \mathrm{C}\right)$ were acquired for $60 \mathrm{mins}$ for high image quality. Initially, scans at $60^{\circ} \mathrm{C}$ were also acquired with a scan time of 60 mins. However, at this acquisition time, through-plane redistribution of water during the compensation mode was observed at capillary pressures above 30 mbar for both GDL types, which lead to an early breakthrough as compared to the scans at $27^{\circ} \mathrm{C}$. The main reason for this effect is expected to be the radiation-induced modification of the wetting behavior of the GDL ${ }^{31}$ making the GDL internal surface more hydrophilic, an effect which is expected to increase with temperature. Therefore, the acquisition time for all scans at $60^{\circ} \mathrm{C}$ that are presented in this study is 9 mins, which is achieved by reducing the number of projections per scan and the number of average and skipped projections. Note that these scans do not show any liquid redistribution throughout the scanning time and breakthrough pressure remained as recorded without imaging. Table III lists the important parameters of the XTM for both short and long scans. Scans of the dry GDLs were taken after the wet scans. The voxel edge length for all scans is $2.3 \mu \mathrm{m}$.

Grayscale 3D images are reconstructed from raw scans using GE reconstruction software. Ternary segmentation of the grayscale images is performed to classify the voxels into solid, water or void. Due to the weak contrast between carbon and water in XTM scans, an extensive workflow is employed for the ternary segmentation process. The workflow is based on the one described in Lamibrac et al., ${ }^{32}$ but with the following modifications:

(i) 3D anisotropic diffusion filter was not used.

(ii) A simpler segmentation process, based on thresholding, is used for both dry and wet GDLs, using the algorithm of Ridler \& Calvard. ${ }^{33}$

(iii) The threshold for water island deletion is 100 pixels, with a connectivity of 26 .

(iv) An additional step is performed in which only the $n$ largest, connected water clusters are retained in the wet images, where $n$ is a number determined based on a trial and error process such that it removes all the noise from the wet image while retaining the water clusters. In this study, $n \approx 5$ as most of the water in the GDL is connected to the pool of water below the GDL.

From the ternary image, water saturation is determined as the ratio of water pixels to the sum of water and void pixels within the RoI.

Modeling of water vapor transport.-In a GDL subjected to water injection from the bottom and gas flow at the top, the steady state equation of water vapor generation due to evaporation and its transport in the GDL can be described ${ }^{34}$ as

$$
\dot{Q}=\frac{\partial}{\partial x}\left(\bar{\rho}_{v}^{g} \bar{u}_{v}\right)
$$

Table III. Main parameters of XTM imaging.

\begin{tabular}{lll} 
& Short scans & Long scans \\
\hline Cell temperature $\left[{ }^{\circ} \mathrm{C}\right]$ & 60 & 27 \\
Voltage $[\mathrm{kV}]$ & 60 & 60 \\
Current $[\mu \mathrm{A}]$ & 200 & 200 \\
Exposure time $[\mathrm{ms}]$ & 500 & 500 \\
Number of projections & 1100 & 1800 \\
Average projections & 1 & 3 \\
Skipped projections & 0 & 1 \\
Total measurement time $[\mathrm{mins}]$ & 9 & 60 \\
Distance to detector $[\mathrm{mm}]$ & 600 & 600 \\
Voxel edge length $[\mu \mathrm{m}]$ & 2.3 & 2.3
\end{tabular}



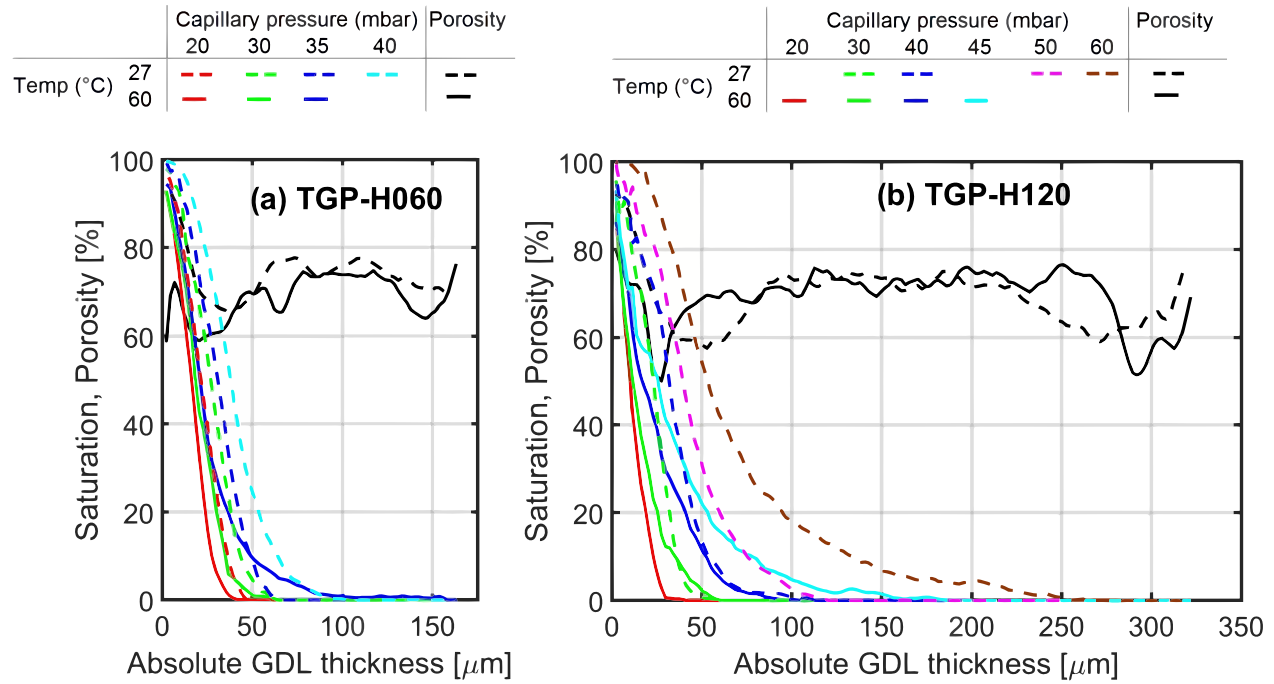

Figure 2. Through-plane saturation profiles in (a) TGP-H060 and (b) TGP-H120 at different capillary pressures and at temperatures of $27^{\circ} \mathrm{C}$ and $60^{\circ} \mathrm{C}$, along with the corresponding porosity profiles of the samples.

where

$$
\bar{\rho}_{v}^{g} \bar{u}_{v}=-\bar{\rho}_{v}^{g} \frac{K_{e f f, g}}{\mu_{g}} \frac{\partial}{\partial x}\left(\bar{P}_{g}^{g}\right)-\bar{\rho}_{g}^{g} D_{e f f} \frac{\partial}{\partial x}\left(\frac{\bar{\rho}_{v}}{\bar{\rho}_{g}}\right)
$$

In Eqs. 2-3, $\dot{Q}\left[\mathrm{~kg} \mathrm{~m}^{-3} \mathrm{~s}^{-1}\right]$ is the volumetric evaporation rate, $\bar{\rho}_{v}$ $\left[\mathrm{kg} \mathrm{m}^{-3}\right]$ and $\bar{\rho}_{g}\left[\mathrm{~kg} \mathrm{~m}^{-3}\right]$ are the water vapor and gas (binary mixture of $\mathrm{N}_{2} / \mathrm{H}_{2}$ and water vapor) densities respectively and the superscript $g$ denotes intrinsic average over the gaseous phase, $\bar{u}_{v}\left[\mathrm{~m} \mathrm{~s}^{-1}\right]$ and $\bar{u}_{g}[\mathrm{~m}$ $\mathrm{s}^{-1}$ ] are the speeds of the vapor and gaseous phase respectively, $K_{\text {eff,g }}$ $\left[\mathrm{m}^{2}\right]$ is the effective permeability of the gaseous phase in the porous medium, $D_{e f f}\left[\mathrm{~m}^{2} \mathrm{~s}^{-1}\right]$ is the effective diffusivity of water vapor in gas in the porous medium, $\mu_{g}\left[\mathrm{~kg} \mathrm{~m}^{-1} \mathrm{~s}^{-1}\right]$ is the viscosity of the gaseous phase and $\bar{P}_{g}^{g}[\mathrm{~Pa}]$ is the average intrinsic pressure of the gaseous phase and $x[\mathrm{~m}]$ is the vapor diffusion distance. The effective properties, $K_{e f f, g}$ and $D_{e f f}$, take into account the reduction of the bulk properties due to the structural properties of the porous medium such as porosity and tortuosity.

From Eqs. 2, 3, it is seen that vapor transport in GDL is driven by gradients of vapor concentration and gas pressure. However, within the porous medium, pressure gradients as well as the overall gas concentration gradients will be negligible. Increasing the temperature is expected to lead to faster evaporation due to larger vapor pressure gradients and higher $D_{\text {eff }}$. Therefore, by combining Eqs. 2 and 3 and neglecting the convective term i.e. first term of RHS of Eq. 3, pure diffusive transport can be described according to Fick's second law as:

$$
\dot{Q}=-D_{e f f} \frac{\partial^{2}}{\partial x^{2}}\left(\bar{\rho}_{v}\right)
$$

In terms of the diffusive vapor flux, $\dot{q}\left[\mathrm{~kg} \mathrm{~m}^{-2} \mathrm{~s}^{-1}\right]$, which we also refer to as the evaporation rate in this study, Eq. 4 can be represented in terms of Fick's first law:

$$
\dot{q}=-D_{e f f} \frac{\partial}{\partial x}\left(\bar{\rho}_{v}\right)
$$

The effective diffusivity of the GDL is determined by modeling diffusive vapor transport with the Explicit Jump solver of the DiffuDict module of GeoDict (Math2Market GmBH, Germany). DiffuDict solves the Laplace equation i.e. the second term of RHS of Eq. 3, in the classical continuum mechanics approach to determine vapor flux due to pure diffusion under a given difference in vapor concentration between the inlet and outlet. The classical approach is used since the Knudsen number $(\mathrm{Kn})$, which is defined as the ratio of the molecular mean free path length to the representative (average) pore size, is much smaller than 1 in case of vapor transport in GDL. ${ }^{35}$ The effective diffusivity is calculated as:

$$
D_{\text {eff }}=\frac{\varepsilon}{\tau} D_{m}
$$

where $\varepsilon / \tau[-]$ is the diffusibility, $\varepsilon[-]$ is the porosity of the medium, $\tau$ [-] is the tortuosity factor and $D_{m}\left[\mathrm{~m}^{2} \mathrm{~s}^{-1}\right]$ is the binary gas diffusion coefficient. While $\varepsilon / \tau$ is an intrinsic structural property independent of the fluid and boundary conditions, $D_{m}$ is dependent on the gas type and temperature. XTM structures of the GDLs are used for the simulations. Diffusive transport is only calculated for the throughplane direction. Dirichlet (fixed) boundary conditions are given at the inlet and outlet boundaries in the direction of diffusion. Periodic boundary conditions are assumed at the other boundaries.

\section{Results and Discussion}

In this section, first the water distribution in the GDL at different capillary pressures and temperatures are analyzed, followed by an analysis of the influence of saturation, temperature, carrier gas type and gas flow rate on the evaporation rate, based on experimental results. The measured evaporation rates are normalized to the region of interest of $1 \mathrm{~mm}^{2}$ (see Figure 1). Finally, experimental observations are complemented with numerical simulations of vapor diffusion in GDL and the physics of vapor diffusion within the GDL is discussed in detail.

Water distribution in the GDL.-Evaporation rates are expected to be a function of the structure of liquid saturation in the GDL, i.e. the size of the liquid-gas and liquid-solid interfaces and the distribution of these interfaces in the GDL, giving rise to transport limitations of vapor in the gas phase and possibly to heat in the solid phase. Therefore, the first step is to analyze water saturation in the throughplane direction of the GDL. In Figure 2, the through-plane saturation profiles for TGP-H060 and TGP-H120 at different capillary pressures are shown for $27^{\circ} \mathrm{C}$ and $60^{\circ} \mathrm{C}$. The experimental conditions are given in Table II. The porosity profiles of the corresponding samples are also plotted in Figure 2.

Although $60^{\circ} \mathrm{C}$ is the reference temperature in this study, saturation profiles for $27^{\circ} \mathrm{C}$ are included since the temperature dependence of water injection in GDL is scarcely investigated. In Figure 2a, it is seen that in TGP-H060 breakthrough is reached at 40 mbar at $27^{\circ} \mathrm{C}$, whereas the corresponding capillary pressure at $60^{\circ} \mathrm{C}$ is $35 \mathrm{mbar}$. Otherwise the saturation profiles are similar. Also for TGP-H120 (Figure $2 \mathrm{~b}$ ), at $27^{\circ} \mathrm{C}$, slightly higher capillary pressures are reached before breakthrough. At $60^{\circ} \mathrm{C}$, above 35 and 45 mbar for TGP-H060 and 
Table IV. Properties of water distribution in the GDL at $60^{\circ} \mathrm{C}$.

\begin{tabular}{clllll} 
GDL & $\begin{array}{c}\text { Pressure } \\
{[\mathrm{mbar}]}\end{array}$ & $\begin{array}{c}\text { Water volume } \\
{\left[\times 10^{-12} \mathrm{~m}^{3}\right]}\end{array}$ & $\begin{array}{c}\text { Water saturation } \\
{[\%]}\end{array}$ & $\begin{array}{c}\text { Front area } \\
{\left[\times 10^{-7} \mathrm{~m}^{2}\right]}\end{array}$ & $\begin{array}{c}\text { Average diffusion distance, } L_{\text {diff }} \\
{[\mu \mathrm{m}]}\end{array}$ \\
\hline TGP-H060 & 20 & 9.7 & 9.5 & 8.3 & 11.4 \\
& 30 & 11.9 & 11.9 & 11.4 & 149.3 \\
TGP-H120 & 35 & 15.8 & 16.4 & 8.1 & 134.9 \\
& 20 & 7.5 & 3.5 & 10.0 & 311 \\
& 30 & 10.0 & 4.7 & 11.7 & 306.7 \\
\\
& 40 & 14.9 & 1.1 & 15.7 & 298.4 \\
\end{tabular}

TGP-H120 respectively, breakthrough is observed at the end of the XTM scans, although there is none at the beginning, even with a reduced scan time of 9 mins. This points to significant water redistribution at these conditions and hence data from these scans are not presented in this study other than in Figure 2. Overall, it seems that temperature has a rather small influence on the water distribution pattern, as also reported by Shrestha \& Gostick. ${ }^{10}$

The saturation profiles show a smooth decrease in saturation from nearly $100 \%$ at the bottom of the GDL (relative thickness $=0$ ) to $0 \%$ at various relative thicknesses depending upon the capillary pressure. This points to the movement of water predominantly through pathways in the through-plane direction. As pointed out by Lamibrac et al. ${ }^{15}$ and Holzer et al., ${ }^{36}$ this is due to the presence of larger throats between the pores in the through-plane direction as compared to those in the inplane direction, which leads to lower constrictivity of pore connections in the through-plane direction to form a percolation path from the bottom to the top of the GDL. Analyzing the saturation profiles at the same temperature and capillary pressure (i.e. 20 and 30 mbar at $60^{\circ} \mathrm{C}$ ), it is observed that water imbibes the two GDLs for a similar absolute distance at same conditions. Therefore, the imbibed volume is also similar at the same capillary pressure for both GDL thicknesses, as seen in Table IV.

In Table IV, more properties of water distribution in the GDLs are given for the different capillary pressures at $60^{\circ} \mathrm{C}$. Note that the water front area is also represented in terms of roughness factor in some studies. ${ }^{27}$ In both the GDLs, it is seen that although the water volume, water saturation and the front area increases significantly with pressure, the average diffusion distance, which is defined as the average of the distances from each voxel of the water front to the top surface of the GDL, shows only a marginal decrease. The water front is visualized in the following section, along with an analysis of its influence on the evaporation rate.

Influence of saturation on evaporation rate.-Figure 3 shows the influence of saturation on evaporation rates in TGP-H060 and TGPH120. The rates given in Figure 3 were obtained for the same samples whose saturation profiles at $60^{\circ} \mathrm{C}$ are shown in Figure 2 and whose water distribution properties are given in Table IV, and are measured both before and after the XTM scans to enable a direct correlation of the evaporation rate with water distribution. In Figure 3, the shaded regions show the standard deviation of the measurements before and after the XTM scans. The increase of the variation at higher capillary pressures implies some influence of water redistribution during the scans.

From Eq. 5, it is seen that the vapor diffusion distance has an inversely linear relationship with the evaporation rate. This relationship is clearly observed when the evaporation rates at the same capillary pressure are compared between TGP-H060 and TGP-H120. However, at 30 mbar, the evaporation rate in TGP-H060 is less than twice of that in TGP-H120, in line with the average diffusion distance (see Table IV) which is also less than a factor of two. To better understand the difference in evaporation rates within the same GDL between the minimum and maximum capillary pressures, in Figs. 4 and 5 the saturation is plotted in the in-plane direction.
Each pixel value in these 2D plots represents the degree of saturation of that pixel along the entire in-plane thickness of the region of interest of the sample. These cumulative plots therefore offer a better way to capture the 3D distribution of water in the GDL than the simple curves in Figure 2. The region below $(0,0)$, between the FEP foil, consists of the pool of water from which injection takes place. From Figures 4 and 5, it is seen that water travels upwards with increasing capillary pressure but the movement of water results in an increase of only 10-20\% saturation along its path. In other words, with increasing capillary pressure, water does not travel as a uniform waterfront, rather it travels in the form of fingering in the larger pores. This movement of water implies that an increase in the water penetration distance in the GDL leads to only a partial decrease in the overall vapor diffusion distance. In other words, a large part of the evaporating front still has the same vapor diffusion distance, which explains the slow increase of evaporation with capillary pressure in Figure 3. This behavior is represented by the average vapor diffusion distances shown in Table IV.

Influence of temperature on evaporation rate.-Evaporation rates in TGP-H060 and TGP-H120 are measured for temperatures between 40 and $80^{\circ} \mathrm{C}$, at 20 mbar liquid pressure and $6 \mathrm{~m} \mathrm{~s}^{-1}$ gas speed. The influence of temperature on the evaporation rate is shown in Figure 6a. Nitrogen $\left(\mathrm{N}_{2}\right)$ and hydrogen $\left(\mathrm{H}_{2}\right)$ are used as carrier gases to discriminate between the vapor transport and possible other limitations of the evaporation rate.

In Figure 6a, as in Figure 3, the shaded regions in the curves correspond to the standard deviation of the measurements since each point is the average of nine measurements (three different samples and three repetitions). The strong influence of temperature on the evaporation rates is clearly observed. The evaporation rates are higher when hydrogen is used as the carrier gas. The lower influence of vapor diffusion lengths as compared to that of the carrier gas type is clearly

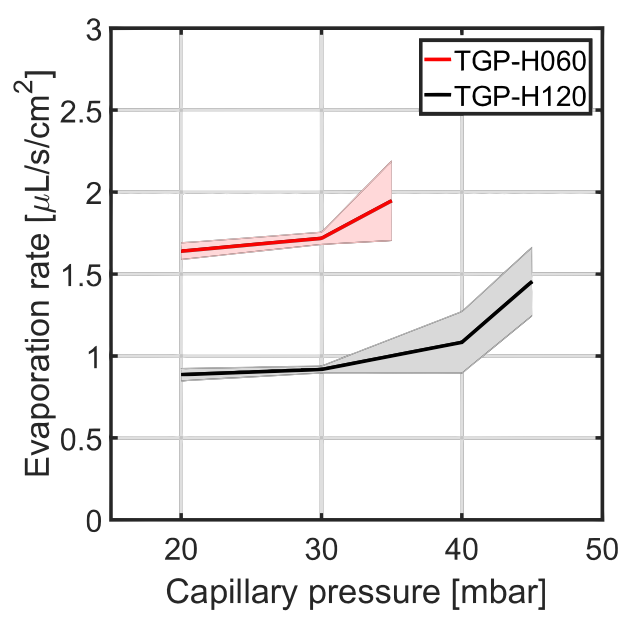

Figure 3. Influence of water saturation on evaporation rate at a temperature of $60^{\circ} \mathrm{C}$ and gas speed of $6 \mathrm{~m} / \mathrm{s}$. 


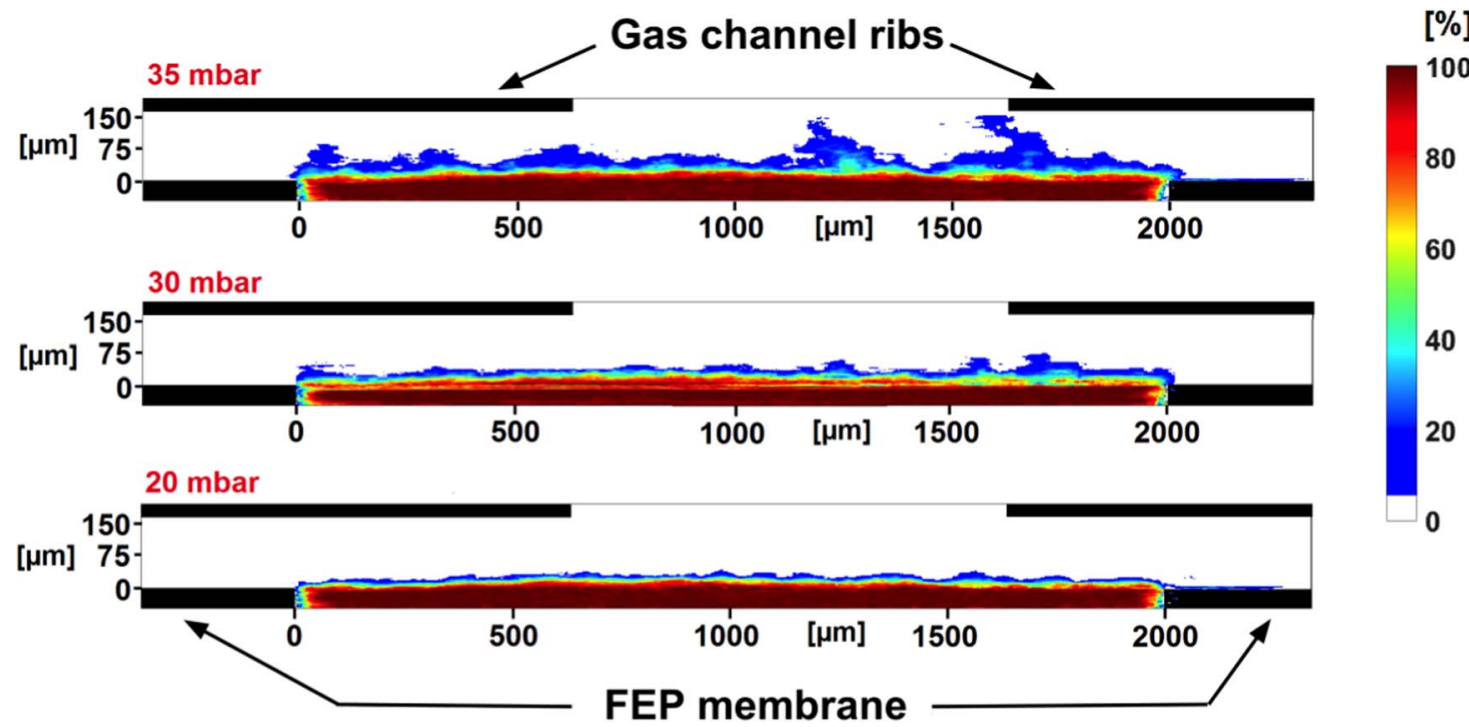

Figure 4. In-plane saturation distribution in TGP-H060 at capillary pressures indicated, at a temperature of $60^{\circ} \mathrm{C}$ and gas speed of $6 \mathrm{~m} / \mathrm{s}$. The gas channel ribs are shown at the top of the GDL, while the FEP foil is shown at the bottom. The region below $(0,0)$, between in the gap of the FEP membrane, consists of the pool of water from which injection takes place.

observed from Figure 6a, and is discussed in more detail in the next section.

Theoretically, the influence of temperature on vapor transport arises from two parameters that appear in Eq. 5: the effective diffusivity, $D_{e f f}$, and the vapor pressure gradient, $\frac{\partial}{\partial x}\left(\bar{\rho}_{v}\right)$. As shown in Eq. 6 , $D_{e f f}$ is proportional to the binary molecular diffusion coefficient, $D_{m}$, which in turn is a function of the temperature. ${ }^{37}$ On the other hand, the saturation vapor concentration, $\bar{\rho}_{v, s a t}$, increases with temperature according to the Antoine equation. Consequently, as temperature increases, the difference in vapor partial pressure near the evaporation front, where $\bar{\rho}_{v}=\bar{\rho}_{v, \text { sat }}$, and the GDL surface exposed to the dry gas flow, where $\bar{\rho}_{v}=0$, also increases. This results in an increase in vapor pressure gradients across the porous structure.

The predicted influence of temperature on the evaporation rate can be mathematically denoted as $\left.\left(D_{m}(T) / D_{m}(T=40)\right) \cdot\left(\bar{\rho}_{v, s a t}(T) / \bar{\rho}_{v, s a t}(T=40)\right)\right|_{T=40} ^{T=80} \quad$ i.e. $\quad$ the predicted curve is the product of $\bar{\rho}_{v, s a t}$ and $D_{m}$ values at each temperature, normalized to their corresponding values at $40^{\circ} \mathrm{C}$. The predicted curve is independent of the carrier gas. Figure $6 b$ also shows the experimental data normalized to the values at $40^{\circ} \mathrm{C}$ i.e. $\left.(\dot{q}(T) / \dot{q}(T=40))\right|_{T=40} ^{T=80}$. Only the mean values of the curves in Figure $6 \mathrm{a}$ are shown in Figure $6 \mathrm{~b}$. The normalized experimental and predicted curves show good agreement. This shows that diffusion limitation is one of the important factors for governing the vapor transport in the porous structures, as also observed by Zenyuk et al. ${ }^{27}$ and indicates that vapor transport has a distinct influence on the overall evaporation rate.

Influence of carrier gas and gas speed on evaporation rate.-The influence of carrier gas and gas speed on the evaporation rates from both GDLs, TGP-H060 and TGP-H120, is analyzed for speeds between 2 and $10 \mathrm{~ms}^{-1}$, at 20 mbar capillary pressure and a temperature of $60^{\circ} \mathrm{C} . \mathrm{N}_{2}$ and $\mathrm{H}_{2}$ are used as the carrier gases. It was observed from Figure 6 that evaporation rates are strongly influenced by diffusive transport. This observation is visible also in Figure 7 a where only a small influence of the gas speed on the evaporation rates is seen.

In Figure $7 \mathrm{~b}$, the experimental and predicted influences of the binary molecular diffusion coefficient, $D_{m}$, are compared for both GDLs. The experimental influence of $D_{m}$ in each GDL is determined by normalizing the evaporation rates of $\mathrm{H}_{2}$ experiments using that of the $\mathrm{N}_{2}$ experiments. For each GDL, the experimental influence of $D_{m}$ can therefore be mathematically denoted as $\left.\left(\dot{q}(U)_{H_{2}} / \dot{q}(U)_{N_{2}}\right)\right|_{U=2} ^{U=10}$.
The normalized rates are in the order of $2-2.5$ for both GDLs at all gas speeds. As $D_{m, H_{2} \mathrm{O}-\mathrm{H}_{2}} / D_{m, \mathrm{H}_{2} \mathrm{O}-\mathrm{N}_{2}}=3.8$, where $D_{m, \mathrm{H}_{2} \mathrm{O}-\mathrm{H}_{2}}=$ $9.92 \times 10^{-5} \mathrm{~m}^{2} \mathrm{~s}^{-1}$ is the water vapor-hydrogen and $D_{m, H_{2} 0-N_{2}}=$ $2.58 \times 10^{-5} \mathrm{~m}^{2} \mathrm{~s}^{-1}$ is the water vapor-nitrogen binary diffusion coefficient at $60^{\circ} \mathrm{C},{ }^{37}$ changing the carrier gas from $\mathrm{N}_{2}$ to $\mathrm{H}_{2}$ should have theoretically resulted in evaporation rates that are 3.8 times faster. This is however not the case in Figure $7 \mathrm{~b}$, where an almost constant misfit is observed at $60^{\circ} \mathrm{C}$ and changing carrier gas speeds.

These observations indicate the possibility of an additional phenomena not considered in the simple one-dimensional interpretation. Different processes and boundary conditions are further discussed in the next section.

Discussion.-From the previous sections, it is seen that the increase in vapor diffusion due to temperature can be predicted by considering the effects of temperature on the binary vapor diffusion coefficient and saturation vapor pressure. However, the same cannot be said of predicting the influence of carrier gas on vapor diffusion, after accounting for the difference in binary diffusion coefficients. To investigate this, simulations of vapor transport in the GDL were carried out. The porous domains used in the simulations are the dry XTM scans of the TGP-H060 and TGP-H120 samples that are used in Figs. 3-7. For simplicity, it is assumed that evaporation takes place only from the pool of water below the porous domain, which is a reasonable approximation for the 20 mbar condition as seen in Figs. 4 and 5. This results in vapor concentration boundary conditions $\bar{\rho}_{v \text {,inlet }}=\bar{\rho}_{v \text {,sat }}$ at the bottom and $\bar{\rho}_{v, \text { outlet }}=0$ at the top of the domain. First, the diffusibility of the GDLs, defined in Eq. 6, is calculated and given in Table V. Note that diffusibility is independent of the carrier gas and vapor concentration boundary conditions. The experimental vapor flux, which is the evaporation rate, at $60^{\circ} \mathrm{C}$ and at a gas speed of $6 \mathrm{~m} / \mathrm{s}$ as calculated from Fig. 7 is also given in Table V. Furthermore, in Table $\mathrm{V}$, using the experimental values of vapor flux, the rate of heat loss as the heat flux, $h\left[\mathrm{~kW} \mathrm{~m}{ }^{-2}\right]$, is calculated as $h=e_{v} \cdot q$, where $e_{v}\left[\mathrm{~kJ} \mathrm{~mol}^{-1}\right]$ is the enthalpy of vaporization of water of $42 \mathrm{~kJ}$ $\mathrm{mol}^{-1}$ at $60^{\circ} \mathrm{C}$. The heat flux represents the cooling at the water front due to evaporation.

The calculated diffusibility agrees well with literature. ${ }^{38,39}$ The significant heat flux values point to a possible cooling effect near the evaporation front and may explain the deviation of the evaporation rate from expected temperature effects at $80^{\circ} \mathrm{C}$ and $\mathrm{H}_{2}$ carrier gas for 

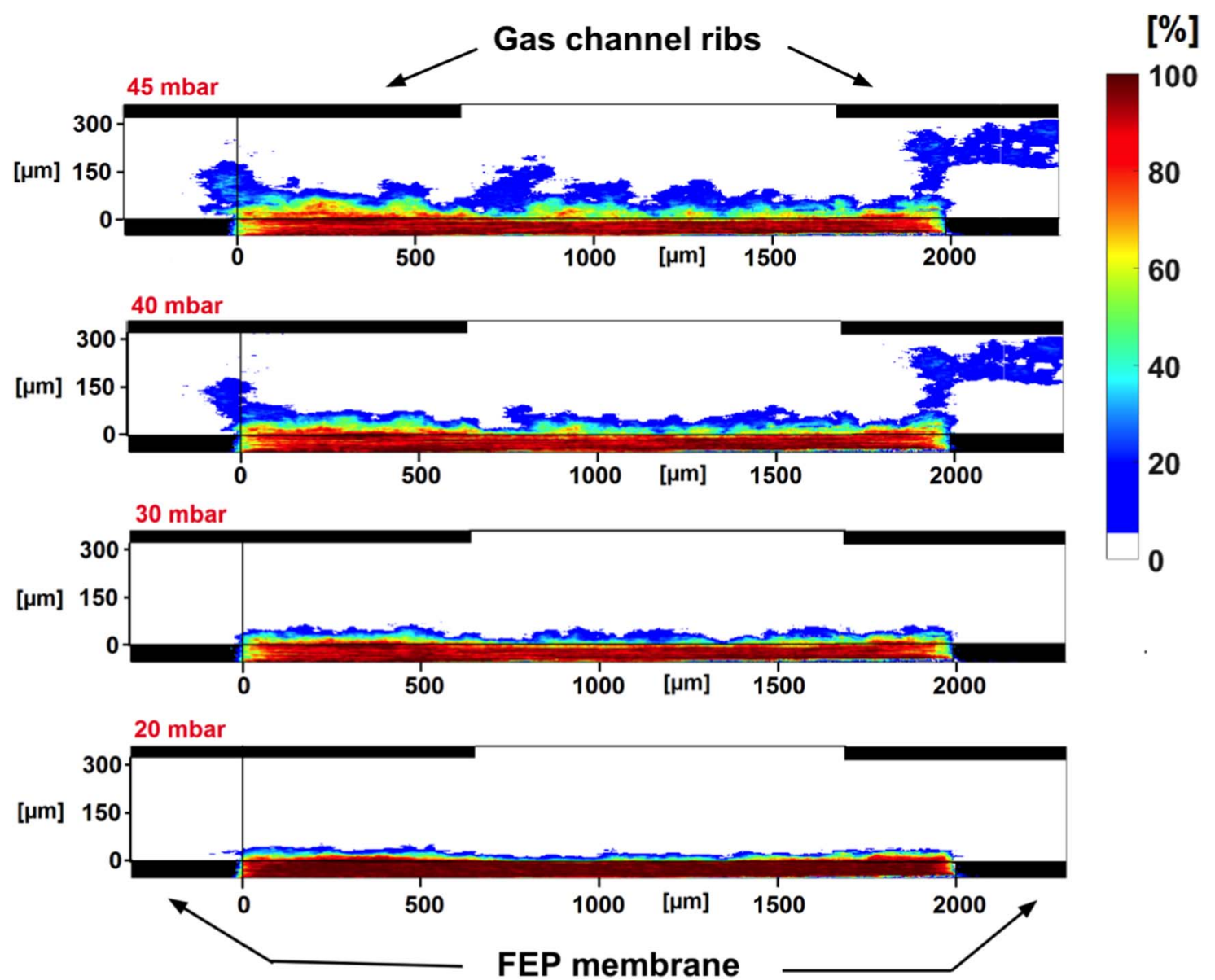

Figure 5. In-plane saturation distribution in TGP-H120 at indicated capillary pressures, at a temperature of $60^{\circ} \mathrm{C}$ and gas speed of $6 \mathrm{~m} / \mathrm{s}$. The gas channel ribs are shown at the top of the GDL, while the FEP foil is shown at the bottom. The region below $(0,0)$, in the gap of the FEP membrane, consists of the pool of water from which injection takes place.

TGP-H060, as seen in Fig. 6b. Moreover, the heat transport within the experimental setup is complex with significant heat transport in the in-plane direction of the GDL (almost ten times higher than that in the through-plane direction ${ }^{40}$ ), heat conduction from the bottom (water side) through the liquid phase itself and from the heated carbon plates, although the GDL is thermally insulated by the FEP foil at the bottom. Though thermal gradients in the setup may be considered as negligible (see Fig. 6b), for a quantitative description of the thermal behavior of the cell and its possible influence on evaporation rates, a dedicated non-isothermal 3D-model is required in future.
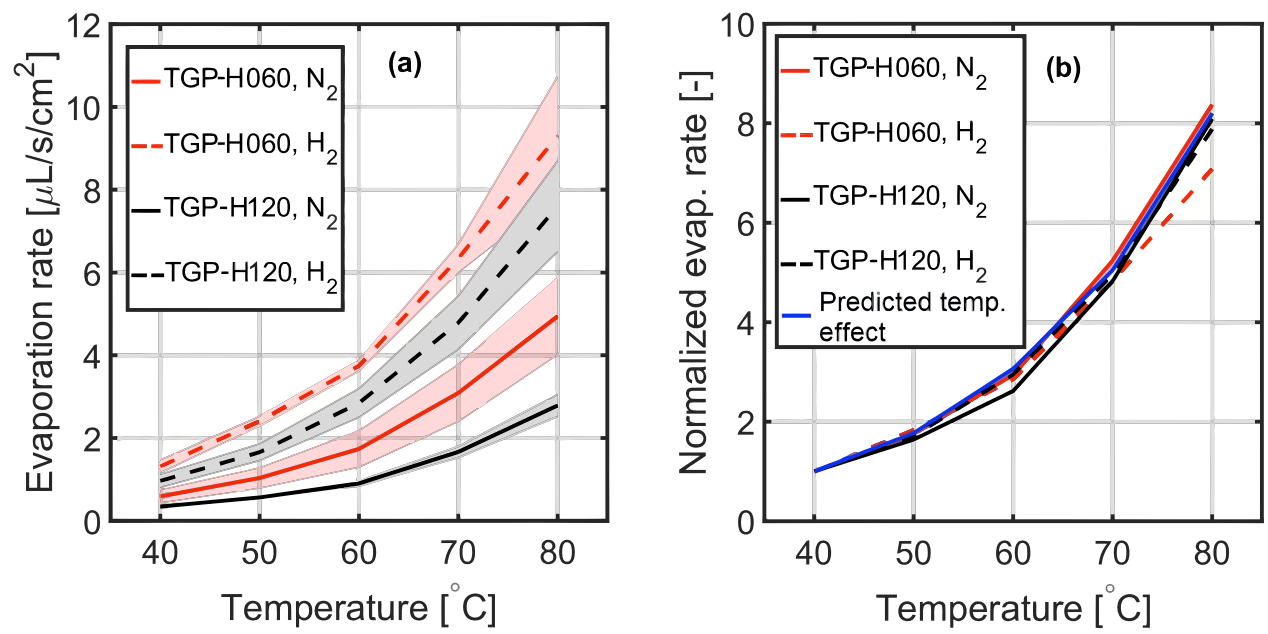

Figure 6. (a) Influence of temperature on the evaporation rate, from TGP-H060 and TGP-H120, using nitrogen $\left(\mathrm{N}_{2}\right)$ and hydrogen $\left(\mathrm{H}_{2}\right)$, shaded areas denoting the standard deviation and (b) comparison of the experimental and predicted influences of temperature on the evaporation rate, where the experimental evaporation rates for each condition are normalized to the corresponding rate at $40^{\circ} \mathrm{C}$. Data obtained at a gas speed of $6 \mathrm{~m} / \mathrm{s}$ and a capillary pressure of $20 \mathrm{mbar}$. 

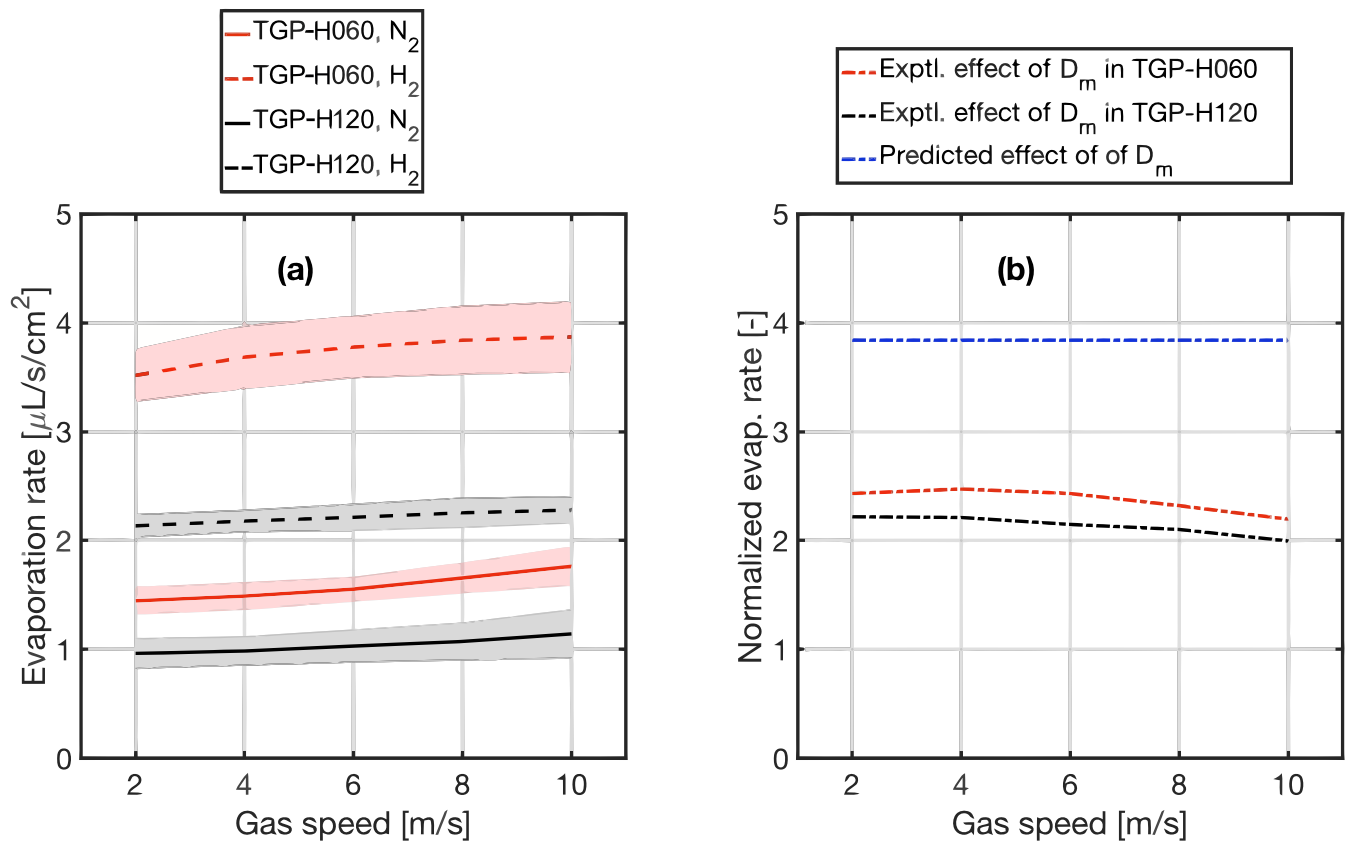

Figure 7. (a) Influence of carrier gas and gas speed on the evaporation rate for TGP-H060 and TGP-H120, using nitrogen $\left(\mathrm{N}_{2}\right)$ and hydrogen $\left(\mathrm{H}_{2}\right)$ shaded areas denoting the standard deviation, and (b) comparison of the experimental and predicted influences of the binary molecular diffusion coefficient $\left(D_{m}\right)$ on the evaporation rate in TGP-H060 and TGP-H120. Data obtained at a temperature of $60^{\circ} \mathrm{C}$ and capillary pressure of $20 \mathrm{mbar}$.

In Figure 8, the experiments presented in Figure 6 are analyzed from a different perspective. In Figure $8 \mathrm{a}$, the experimental and predicted influences of $L_{d i f f}$, the average diffusion length, on the evaporation rate are presented for both the carrier gases used. For a given carrier gas, the experimental influence of $L_{\text {diff }}$ is determined by calculating the ratio of the evaporation rates in TGP-H060 and TGP-H120 and can be mathematically denoted as $\left.\left(\dot{q}(T)_{T G P-H 060} / \dot{q}(T)_{T G P-H 120}\right)\right|_{T=40} ^{T=80}$. The predicted influence is the ratio of the average diffusion lengths of TGP-H060 and TGP-H120 at 20 mbar, as given in Table IV. According to Eq. 5, the smaller thickness of TGP-H060 as compared to
TGP-H120 should lead to a higher concentration gradient and thus to a higher diffusive vapor flux in the former. However, the predicted effect of $L_{\text {diff }}$ is larger than what is experimentally observed for both carrier gases, with values being just below 2 for nitrogen and values between 1.2 and 1.4 for hydrogen. Thermal effects may play a role here as the evaporation rates with hydrogen are significantly higher. The observation that the evaporation rates do not follow the ratio of the binary molecular diffusion coefficients $D_{m, H_{2} 0-H_{2}} / D_{m, H_{2} 0-N_{2}}$ as shown in Figure $7 \mathrm{~b}$ is confirmed when plotting the ratio $\left.\left(\dot{q}(T)_{H_{2}} / \dot{q}(T)_{N_{2}}\right)\right|_{T=40} ^{T=80}$ for the evaporation rates from the temperature variation (see
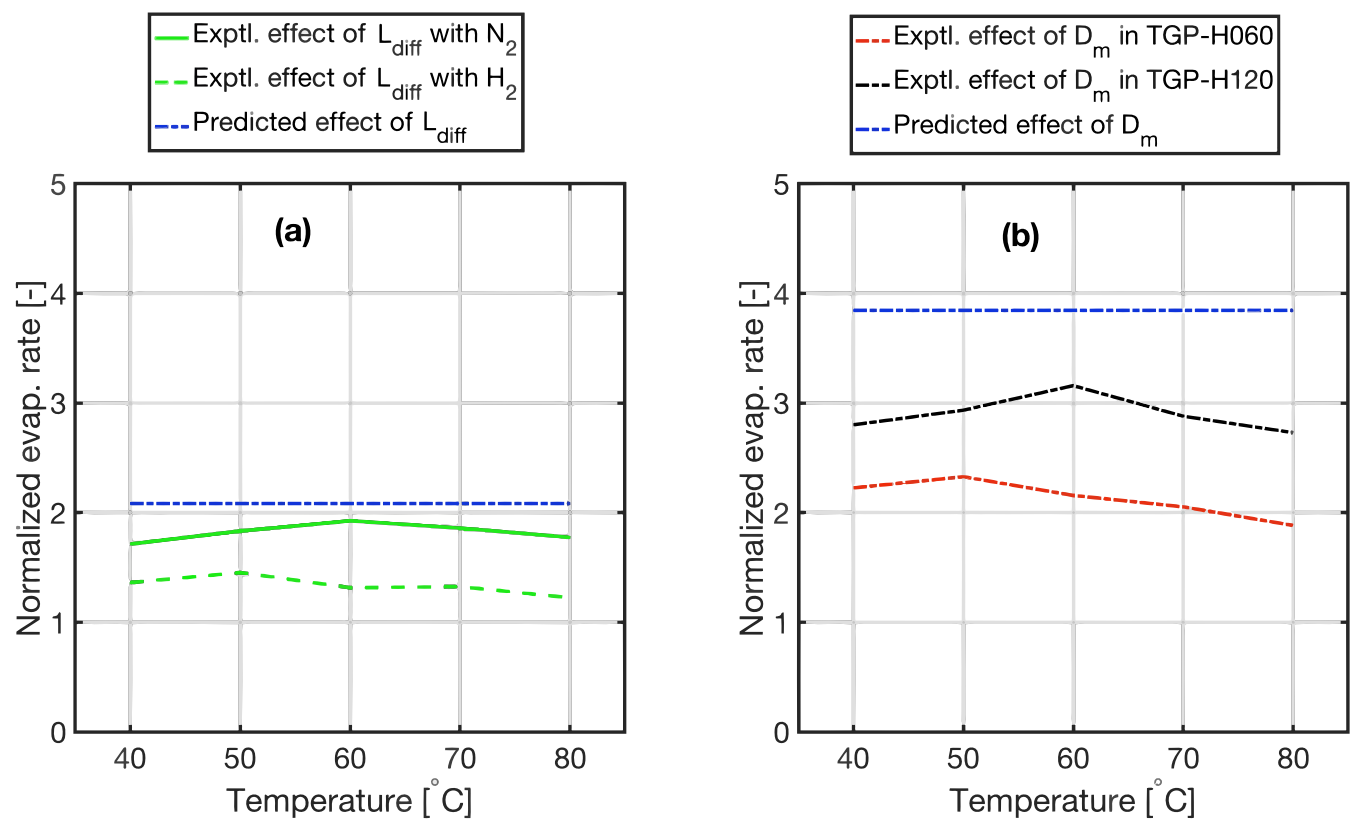

Figure 8. (a) Comparison of the experimental and predicted influences of average diffusion distance $\left(\mathrm{L}_{\text {diff }}\right)$ on the evaporation rate, in case of both nitrogen $\left(\mathrm{N}_{2}\right)$ and hydrogen $\left(\mathrm{H}_{2}\right)$ carrier gases, and (b) comparison of the experimental and predicted influences of the binary molecular diffusion coefficient $\left(D_{m}\right)$ on the evaporation rate in TGP-H060 and TGP-H120. Data is from the same experiments of Figure 6 i.e. gas speed of 6 m/s and capillary pressure of 20 mbar. 


\section{Table V. Transport parameters calculated from vapor diffusion modeling and heat flux calculated from experimental vapor flux at cell temperature} of $60^{\circ} \mathrm{C}$ and gas speed of $6 \mathrm{~m} / \mathrm{s}$.

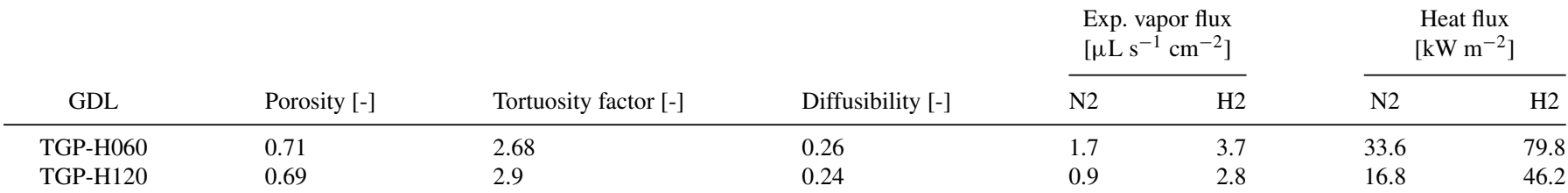

Figure 8b). However, while TGP-H060 and TGP-H120 show an almost equal deviation from the predicted effect of the molecular diffusion coefficient in Figure $7 \mathrm{~b}$, the variation is higher in Figure 8b, which could be due to the standard deviation in the experiments.

Though the water injection area and channel geometry were chosen to have as clear boundary conditions as possible, the remaining contributions of boundary effects of water injection area geometry on the evaporation rate are so far not fully understood. This includes contributions from evaporation under the rib domains and mixed inplane-through-plane diffusion of vapor above the water injection domain boundary.

The evaporation rate measurements at a range of temperatures and gas flow velocities using different carrier gases and GDL thicknesses, but similar water saturation levels at 20 mbar, give indications that liquid water evaporation is not a purely diffusion-limited process. Safi et al. ${ }^{28}$ reported for SGL 24 BA type GDL that the velocity component of the diffusive vapor flux from evaporation at $30^{\circ} \mathrm{C}$ equals the velocities of the convective boundary layer flow in the GDL at a depth of about $50 \mu \mathrm{m}$ from the GDL surface for $1.6 \mathrm{~m} / \mathrm{s}$ channel gas flow velocity. For Toray type GDLs at the presented gas velocities, the influence of the convective boundary layer in the GDL is unknown and difficult to estimate. But the convective boundary layer velocity profile can be expected to be similar for the different GDL thickness and carrier gases, which would lead to a similar reduction of the diffusive length $L_{\text {diff. }}$. Consequently, the ratio of $L_{\text {diff }}$ of TGP-H120 and TGP-H060 should further increase and the difference between the experimental and predicted values will be even higher.

\section{Conclusions and Outlook}

Evaporation of water in GDLs is an important process influencing water management and due to evaporative cooling, it could even be used as a combined heat and water management technique. In this study, evaporation rates from Toray TGP-H060 and TGP-H120 GDL materials were measured for different temperatures, gas flow rates, carrier gases and GDL water saturation levels. Evaporation rates are correlated with water distribution profiles in the GDL, obtained using $\mathrm{X}$-ray tomographic microscopy imaging (XTM).

The increase of evaporation rates with increasing temperature can be predicted by considering the influence of temperature on vapor diffusion (concentration gradient and diffusion coefficient) for the present setup. The influence of the channel gas speeds on the evaporation rate is weak, as only a slight increase with gas velocity was observed. This means that differential conditions for the relative humidity of the gas flow in the cell was achieved. When comparing evaporation rates with different carrier gases, it is seen that the change in evaporation rates is not proportional to the change in the binary diffusion coefficient. Furthermore, on doubling the GDL thickness, the evaporation rates do not follow inverse proportionality as is expected from purely diffusion-limited systems. Due to the possibility of entrainment of carrier gas inside the GDL, pure diffusion-based interpretation of the experimental data may be inappropriate and misleading.

As next steps, the influence of the water pool geometry boundary conditions, different GDL substrate types and conditions closer to operando state using humidified gas etc. on the evaporation rates should be explored. On the modeling side, a multi-physics simulation of evaporation in GDL that couples heat transport with diffusive and convective mass transport is needed to achieve a more accurate picture of the limiting factors of water evaporation in the GDL.

\section{Acknowledgments}

The authors thank the Competence Center for Energy and Mobility (CCEM) of the ETH Domain in Switzerland, the Swiss Federal Office of Energy (BFE) and swisselectric research (SER) for financial support of the project ADMIST (Advanced Understanding of Micro Structures in Fuel Cells and Batteries through X-ray Imaging; project number: 912), in whose framework the present work was carried out. The authors also gratefully acknowledge Thomas Gloor for software, electronic and technical assistance, and Marcel Hottiger for the precise machining of the setups, as well as M.A. Safi, N. Prasianakis and I. Mantzaras for discussions on multicomponent mass transport in GDLs.

\section{ORCID}

Sreeyuth Lal (i) https://orcid.org/0000-0002-6366-4264

Jens Eller (10) https://orcid.org/0000-0002-9348-984X

Felix N. Büchi (iD) https://orcid.org/0000-0002-3541-4591

\section{References}

1. J. St-Pierre, D. P. Wilkinson, S. Knights, and M. L. Bos, "Relationships between water management, contamination and lifetime degradation in PEFC," J. New Mater. Electrochem. Syst., 3(2), 99 (2000).

2. R. Flückiger, S. A. Freunberger, D. Kramer, A. Wokaun, G. G. Scherer, and F. N. Büchi, "Anisotropic, effective diffusivity of porous gas diffusion layer materials for PEFC," Electrochim. Acta, 54(2), 551 (2008).

3. S. Raman, K. B. Iyeswaria, S. Narasimhan, and R. Rengaswamy, "Effects of water induced pore blockage and mitigation strategies in low temperature PEM fuel cells A simulation study," Int. J. Hydrogen Energy), 1 (2017).

4. A. Fly and R. H. Thring, "ScienceDirect A comparison of evaporative and liquid cooling methods for fuel cell vehicles," Int. J. Hydrogen Energy, 41(32), 14217 (2016).

5. D. L. Wood, J. S. Yi, and T. V Nguyen, "Effect of direct liquid water injection and interdigitated flow field on the performance of proton exchange membrane fuel cells," Electrochim. Acta, 43(24), 3795, (1998).

6. A. Warburton, D. Mossop, B. Burslem, and P. Rama, "Development of an Evaporatively Cooled Hydrogen Fuel Cell System and its Vehicle Application," SAE Tech. Pap., vol. 2013, 1-4 (2013)

7. S. H. Hwang and M. S. Kim, "An experimental study on the cathode humidification and evaporative cooling of polymer electrolyte membrane fuel cells using direct water injection method at high current densities," Appl. Therm. Eng., 99, 635 (2016).

8. A. Z. Weber and R. M. Darling, "Understanding porous water-transport plates in polymer-electrolyte fuel cells," J. Power Sources, 168(1 SPEC. ISS.), 191 (2007).

9. A. Fly and R. H. Thring, "Temperature regulation in an evaporatively cooled proton exchange membrane fuel cell stack," Int. J. Hydrogen Energy, 40(35), 11976 (2015).

10. K. P. Shrestha and J. T. Gostick, "Measurement of Capillary Pressure Curves in GDLs at Elevated Temperatures," ECS Trans., 50(2), 469 (2012).

11. A. Forner-Cuenca, J. Biesdorf, L. Gubler, P. M. Kristiansen, T. J. Schmidt, and P. Boillat, "Engineered Water Highways in Fuel Cells: Radiation Grafting of Gas Diffusion Layers," Adv. Mater, 27(41), 6317 (2015).

12. J. T. Gostick, M. W. Fowler, M. a. Ioannidis, M. D. Pritzker, Y. M. Volfkovich, and a. Sakars, "Capillary pressure and hydrophilic porosity in gas diffusion layers for polymer electrolyte fuel cells," J. Power Sources, 156(2), 375 (2006)

13. T. V. Nguyen, G. Lin, H. Ohn, and X. Wang, "Measurement of Capillary Pressure Property of Gas Diffusion Media Used in Proton Exchange Membrane Fuel Cells," Electrochem. Solid-State Lett., 11(8), B127 (2008).

14. J. T. Gostick, M. A. Ioannidis, M. W. Fowler, and M. D. Pritzker, "Wettability and capillary behavior of fibrous gas diffusion media for polymer electrolyte membrane fuel cells," J. Power Sources, 194(1), 433 (2009). 
15. A. Lamibrac, J. Roth, M. Toulec, F. Marone, M. Stampanoni, and F. N. Büchi, "Characterization of Liquid Water Saturation in Gas Diffusion Layers by X-Ray Tomographic Microscopy," J. Electrochem. Soc., 163(3), F202 (2016).

16. R. Flückiger, F. Marone, M. Stampanoni, A. Wokaun, and F. N. Büchi, "Investigation of liquid water in gas diffusion layers of polymer electrolyte fuel cells using X-ray tomographic microscopy," Electrochim. Acta, 56(5), 2254 (2011).

17. O. Chapuis, M. Prat, M. Quintard, E. Chane-Kane, O. Guillot, and N. Mayer, "Twophase flow and evaporation in model fibrous media. Application to the gas diffusion layer of PEM fuel cells," J. Power Sources, 178(1), 258 (2008).

18. K. T. Cho and M. M. Mench, "Fundamental characterization of evaporative water removal from fuel cell diffusion media," J. Power Sources, 195(12), 3858 (2010).

19. K. T. Cho and M. M. Mench, "Effect of material properties on evaporative water removal from polymer electrolyte fuel cell diffusion media," J. Power Sources, 195(19), 6748 (2010).

20. S. Basu, C.-Y. Wang, and K. S. Chen, "Phase Change in a Polymer Electrolyte Fuel Cell," J. Electrochem. Soc., 156(6), B748 (2009).

21. F. Jiang and C.-Y. Wang, "Numerical modeling of liquid water motion in a polymer electrolyte fuel cell," Int. J. Hydrogen Energy, 39(2), 942 (2014).

22. B. Straubhaar, J. Pauchet, and M. Prat, "Water transport in gas diffusion layer of a polymer electrolyte fuel cell in the presence of a temperature gradient. Phase change effect," Int. J. Hydrogen Energy, 40(35), 11668 (2015).

23. J. Eller, T. RoseF́n, F. Marone, M. Stampanoni, A. Wokaun, and F. N. Buüchi, "Progress in In Situ X-Ray Tomographic Microscopy of Liquid Water in Gas Diffusion Layers of PEFC," J. Electrochem. Soc., 158(8), B963 (2011).

24. J. Eller, J. Roth, F. Marone, M. Stampanoni, and F. N. Büchi, "Operando Properties of Gas Diffusion Layers: Saturation and Liquid Permeability," J. Electrochem. Soc., 164(2), F115 (2017).

25. T. Rosen, J. Eller, J. Kang, N. I. Prasianakis, J. Mantzaras, and F. N. Buchi, "Saturation Dependent Effective Transport Properties of PEFC Gas Diffusion Layers," $J$. Electrochem. Soc., 159(9), F536 (2012).

26. I. V. Zenyuk, D. Y. Parkinson, G. Hwang, and A. Z. Weber, "Probing water distribution in compressed fuel-cell gas-diffusion layers using X-ray computed tomography," Electrochem. commun., 53, 24 (2015).

27. I. V. Zenyuk et al., "Investigating Evaporation in Gas Diffusion Layers for Fuel Cells with X-ray Computed Tomography," J. Phys. Chem. C, p. acs.jpcc.6b10658, (2016).
28. M. A. Safi, N. I. Prasianakis, J. Mantzaras, A. Lamibrac, and F. N. Büchi, "Experimental and pore-level numerical investigation of water evaporation in gas diffusion layers of polymer electrolyte fuel cells," Int. J. Heat Mass Transf., 115, 238 (2017).

29. J. Lobato, P. Cañizares, M. A. Rodrigo, C. Ruiz-López, and J. J. Linares, "Influence of the Teflon loading in the gas diffusion layer of PBI-based PEM fuel cells," J. Appl. Electrochem., 38(6), 793 (2008).

30. G. G. Park, Y. J. Sohn, T. H. Yang, Y. G. Yoon, W. Y. Lee, and C. S. Kim, "Effect of PTFE contents in the gas diffusion media on the performance of PEMFC," J. Power Sources, 131(1-2), 182 (2004).

31. J. Roth, J. Eller, and F. N. Büchi, "Effects of synchrotron radiation on fuel cell materials," J. Electrochem. Soc., 159(8), F449 (2012).

32. A. Lamibrac, J. Roth, M. Toulec, F. Marone, M. Stampanoni, and F. N. Büchi, "Characterization of Liquid Water Saturation in Gas Diffusion Layers by X-Ray Tomographic Microscopy," J. Electrochem. Soc., 163(3), F202 (2015).

33. S. Ridler and T. W. Calvard, "Picture Thresholding Using an Iterative Slection Method," IEEE Trans. Syst. Man Cybern., 8(8), 630 (1978).

34. S. B. Nasrallah and P. Perre, "Detailed study of a model of heat and mass transfer during convective drying of porous media," Int. J. Heat Mass Transf., 31(5), 957 (1988).

35. J. H. Nam and M. Kaviany, "Effective diffusivity and water-saturation distribution in single- and two-layer PEMFC diffusion medium," Int. J. Heat Mass Transf., 46(24), 4595 (2003)

36. L. Holzer et al., "Microstructure-property relationships in a gas diffusion layer (GDL) for Polymer Electrolyte Fuel Cells, Part I: effect of compression and anisotropy of dry GDL," Electrochim. Acta, 227, 419 (2017)

37. R. B. Bird, W. E. Stewart, and E. N. Lightfoot, Transport Phenomena, 2nd ed. New York: John Wiley \& Sons, 2002

38. J. M. Lamanna and S. G. Kandlikar, "Determination of effective water vapor diffusion coefficient in pemfc gas diffusion layers," Int. J. Hydrogen Energy, 36(8), 5021 (2011).

39. N. Zamel et al., "Experimental measurements of effective diffusion coefficient of oxygen-nitrogen mixture in PEM fuel cell diffusion media," Chem. Eng. Sci., 65(2), 931 (2010).

40. N. Zamel, E. Litovsky, S. Shakhshir, X. Li, and J. Kleiman, "Measurement of inplane thermal conductivity of carbon paper diffusion media in the temperature range of $-20^{\circ} \mathrm{C}$ to $+120^{\circ} \mathrm{C}$," Appl. Energy, 88(9), 3042 (2011). 